\title{
Sosialisasi Pemilu 2019 Untuk Pemilih Pemula Kota Depok
}

\author{
Khikmatul Islah $^{\mathrm{a}, 1, *}$, Juardi ${ }^{\text {b,2 }}$, Eman Sulaeman Nasim ${ }^{\text {b,3 }}$ \\ a,b Fakultas Ilmu Administrasi, Institut Ilmu Sosial dan Manajemen STIAMI \\ 1 islahzone@gmail.com* \\ * corresponding author
}

\section{ARTICLE INFO}

Keywords

First-Time Voter;

General Election;

Socialization.

\begin{abstract}
The year 2019 was the year of the people's party in Indonesia, where every Indonesian citizen got their right to deliver their aspiration through the general election which would be held on April 17, 2019. This general election would be held simultaneously to elect the president and vice president and also the council members. Slightly different from the previous general election which had separated agenda between the president and vice president and the council members. The role of General Election Commission (KPU) in the general election was as an organizer that very important in succeeding the general election. As the organizer, KPU also had a big role in encouraging people to actively participate in casting their votes. One of the ways carried out by KPU Depok in order to encourage the voters of the Depok city to cast their votes was by conducting socialization. In the 2019 general election, one of the targets of the socialization conducted by KPU Depok was the firsttime voters. Of the total number of 2,466 first-time voters registered as the Final Voters List (DPT), KPU Depok was targeting 100\% of the first-time voters to participate in the April 17, 2019 general election. Various ways were made by KPU Depok to socialize and educate firsttime voters all about the election. One of them was to collaborate with STIAMI Institute in order to socialize the 2019 general election for the first-time voters in Depok. The specific target to be achieved in the community service was to encourage the first-time voters to come to the polling stations (TPS) to cast their voting rights in the 2019 general election, also educate them the proper way to cast their votes in the 2019 general election. The method used in this community service was by socializing and conducting interview about the 2019 general election.
\end{abstract}

\section{PENDAHULUAN}

Penyelenggaraan pemilihan umum merupakan bagian dari unsur negara demokrasi.Komisi Pemilihan Umum (KPU) sebagai penyelenggara pemilihan umum memiliki tugas dalam mensukseskan penyelenggaraan pesta demokrasi ini yang dilaksanakan setiap lima tahun sekali. Bersama dengan Badan Pengawasan Pemilihan Umum (BAWASLU) dan Dewan Kehormatan Penyelenggara Pemilihan Umum (DKPP), Komisi Pemilihan Umum (KPU) bekerjasama dalam menyelenggarakan pemilihan umum 2019 ini agar berjalan sesuai asas jurdil (jujur dan adil) dan luber (langsung, umum, bebas, dan rahasia).

Kementerian Dalam Negeri (Kemendagri) mencatat ada 5.035.887 orang pemilih pemula pada Pemilu 2019. Data ini masuk dalam Daftar Penduduk Pemilih Potensial Pemilu (DP4). Dalam DP4 terdapat pemilih pemula yang akan berusia 17 tahun tanggal 1 Januari 2018 sampai dengan 17 April 2019 sebanyak 5.035.887 jiwa.

Komisi Pemilihan Umum (KPU) Kota Depok sebagai penyelenggara pemilihan umum pada tingkat daerah juga berusaha mensukseskan pemilihan umum 2019 ini. Salah satu cara yang dilakukan adalah dengan melakukan sosialisasi. Sosialisasi dilakukan Komisi Pemilihan Umum (KPU) Kota Depok kepada seluruh lapisan masyarakat, baik masyarakat umum maupun lembaga atau komunitas yang ada di Kota Depok, termasuk ke partai peserta pemilihan umum serta para calon anggota legislatifnya.

Dari total Daftar Pemilih Tetap (DPT) Kota Depok sebanyak 1.309.738, ada sejumlah 2466 pemilih pemula yang terdaftar sebagai Daftar Pemilih Tetap (DPT). Terkait dengan pemilihan 
umum, dalam penyelenggaraan tahun 2019 ini KPU Kota Depok mentargetkan 100\% pemilih pemula akan turut berpartisipasi dalam pemilihan umum 17 April 2019 ini.

Dalam pelaksanaan sosialisasinya, KPU Kota Depok melakukan kerjasama dengan beberapa pihak. Sasaran sosialisasinya pun berbagai kalangan masyarakat. Salah satu yang menjadi fokus sosialisasi adalah para pemilih pemula. Sebab pemilih pemula ini masih perlu untuk diedukasi, diajak dan diarahkan agar turut aktif dalam menyalurkan hak pilihnya.

Pengertian dari pemilih pemula (first-time voters) itu sendiri adalah warga negara yang berdasarkan ketentuan perundang-undangan telah memenuhi syarat sebagai pemilih, yang untuk pertama kalinya menggunakan hak pilih pada suatu pemilihan umum (pemilu nasional atau pilkada). Pemilih pemula ini bisa luas dan beragam cakupannya, terdiri atas kalangan pelajar dan mahasiswa yang berada dalam rentang usia antara 17-22 tahun (dihitung berdasarkan pelaksanaan pemilu 5 tahunan), juga termasuk kalangan muda yang berada dalam rentang usia tersebut; warga negara yang sudah/pernah menikah meski usianya belum mencapai 17 tahun, dan para pensiunan TNI/Polri. (Sutisna, 2017)

Secara politik, pemilih pemula merupakan kelompok yang baru pertama kali menggunakan hak pilihnya. Dalam hal ini, orientasi politik pemilih pemula sering kali dinamis dan bisa berubahubah mengikuti kondisi dan faktor yang mempengaruhinya. Akan tetapi, suara pemilih pemula ini juga menjanjikan dalam pemilihan umum. Setiap peserta pemilihan umum memiliki kesempatan untuk mendapatkan keuntungan suara pemilih pemula. (Nur Wardhani, 2018)

Pemilih pemula ini merupakan pemilih milenial yang penting untuk diberikan pendidikan politik. Dikutip dari berita republika.go.id, Komisioner KPU Pramono Ubaid Tanthowi menyebutkan bahwa pemilih milenial menjadi penentu siapa pemimpin kedepannya dan ke mana arah bangsa akan dibangun. Data KPU menunjukkan bahwa pemilih milenial ini jumlahnya mencapai 70-80 juta dari sekitar 193 juta pemilih atau sekitar 35-40 persen yang memiliki pengaruh besar terhadap hasil pemilu. (Harnom, Syahrizal, \& Valentina, 2019)

Suara pemilih pemula ini perlu diarahkan agar tidak salah dalam menyalurkan aspirasinya sehingga pemilihan umum berjalan sesuai dengan asas demokrasi. Maka dari itu, Institut STIAMI mendukung adanya sosialisasi pemilihan umum kepada pemilih pemula. Institut STIAMI sebagai insan akademik memiliki kewajiban untuk turut mengedukasi masyarakat terkait pemilihan umum, terutama edukasi kepada pemilih pemula. Institut STIAMI bekerjasama dengan KPU Kota Depok untuk melakukan sosialisasi kepada pemilih pemula tentang pemilihan umum 2019.

\section{METODE PELAKSANAAN KEGIATAN}

\section{Tujuan Kegiatan}

Adapun tujuan dari sosialisasi Pemilu kepada pemilih pemula ini adalah sebagai berikut:

1. Memberikan pemahaman kepada pemilih pemula tentang informasi pelaksanaan dan prosedur dalam Pemilu 2019.

2. Men ingkatkan kesadaran pemilih pemula untuk datang ke TPS dan menyalurkan suara nya dalam Pemilu 2019.

\section{Metode Pelaksanaan Kegiatan}

1. Sosialisasi

PKM Sosialisasi Pemilu 2019 ini dilaksanakan dengan metode sosialisasi kepada siswa kelas XII sekolah SMA atau sederajat di Kota Depok.

2. Diskusi

Dalam PKM sosialisasi ini juga dilakukan diskusi. Diskusi dilakukan pada saat sosialisasi dilaksanakan bersama dengan Komisioner KPU Kota Depok. Diskusi berjalan dengan adanya Tanya jawab antara peserta dengan pengisi sosialisasi yang berasal dari pihak KPU dan STIAMI.

\section{HASIL DAN PEMBAHASAN}

\section{Proses Kerjasama}

Sebelum Sosialisasi Pemilu 2019 ini dilaksanakan, telah dilakukan kerjasama antara Institut STIAMI dengan KPU Kota Depok. 


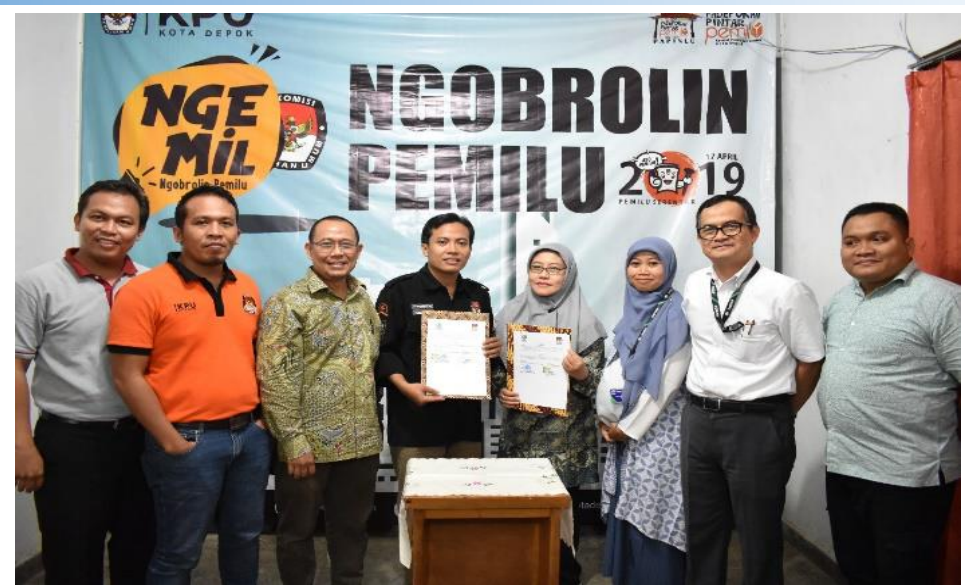

Gambar 1. Penandatanganan kerjasama antara Institut STIAMI dan KPU Kota Depok

Selanjutnya setelah penandatanganan kerjasama antara Institut STIAMI dengan KPU Kota Depok, kegiatan Sosialisasi Pemilu 2019 ini dapat terlaksana dengan mendatangi beberapa sekolah SMA/sederajat di Kota Depok.

\section{Bentuk Kegiatan, Waktu, Tempat, dan Foto Kegiatan}

Adapun sekolah yang diberikan sosialisasi adalah sebagai berikut:

1. Hari/tanggal: Senin, 18 Februari 2019

- Tempat: SMA dan SMK Budi Utomo Kota Depok

- Waktu: 07.00 - selesai

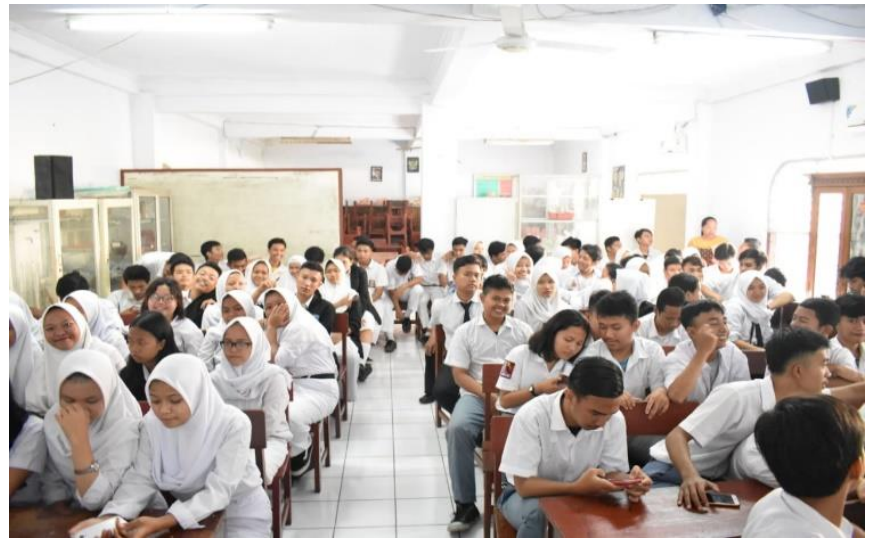

Gambar 2. Pelaksanaan sosialisasi di SMA dan SMK Budi Utomo Kota Depok.

2. Hari/tanggal: Senin, 18 Februari 2019

- Tempat: SMA Master Kota Depok

- Waktu: 14.00 - selesai

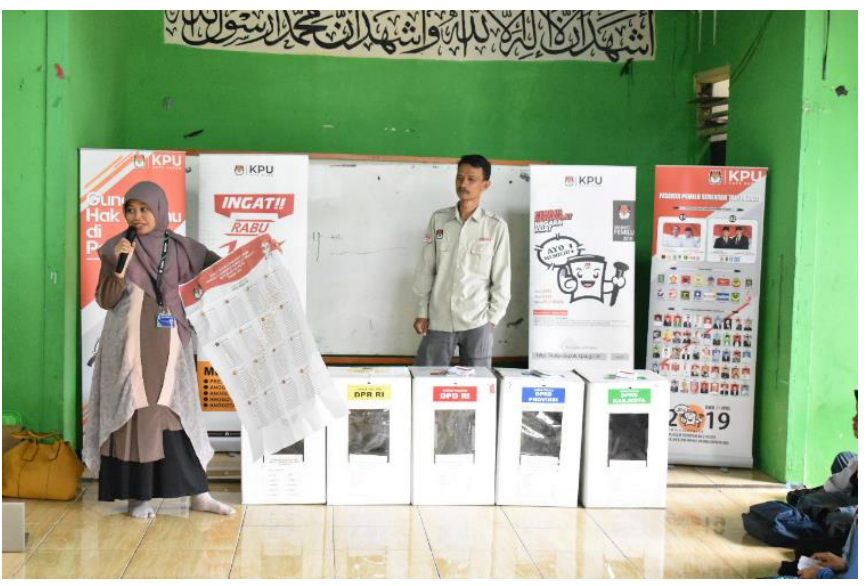

Gambar 3. Pelaksanaan sosialisasi di SMA Master Kota Depok. 
3. Hari/tanggal: Jumat, 22 Februari 2019

- Tempat: SMK YAJ Kota Depok

- Waktu: 07.00 - selesai

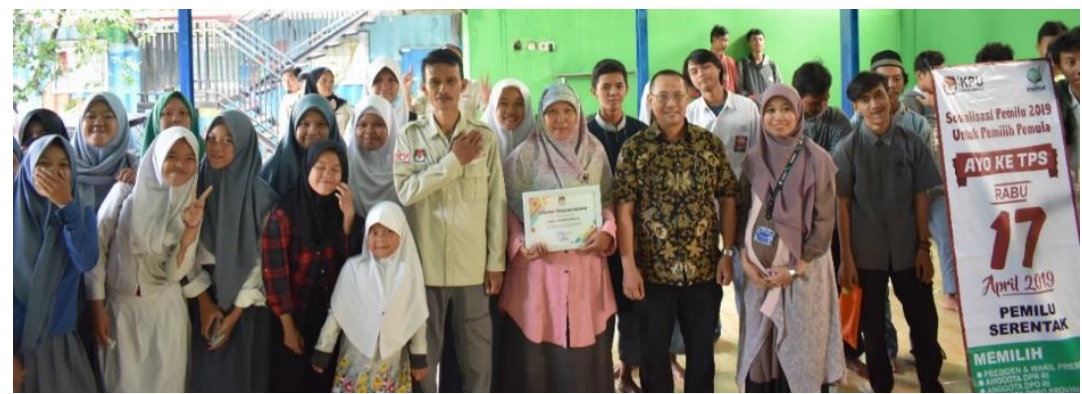

Gambar 4. Pelaksanaan sosialisasi di SMK YAJ Kota Depok.

4. Hari/tanggal: Jumat, 22 Februari 2019

- Tempat: SMK Tritura Kota Depok

- Waktu: 14.00 - selesai

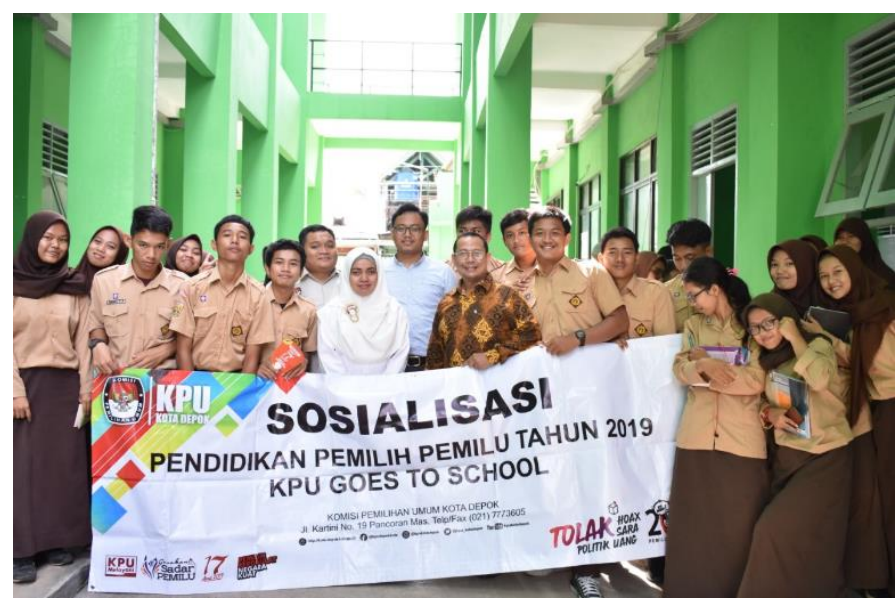

Gambar 5. Pelaksanaan sosialisasi di SMA dan SMK Budi Utomo Kota Depok.

5. Hari/tanggal: Rabu, 27 Februari 2019

- Tempat: SMA 13 Kota Depok

- Waktu: 08.30 - selesai

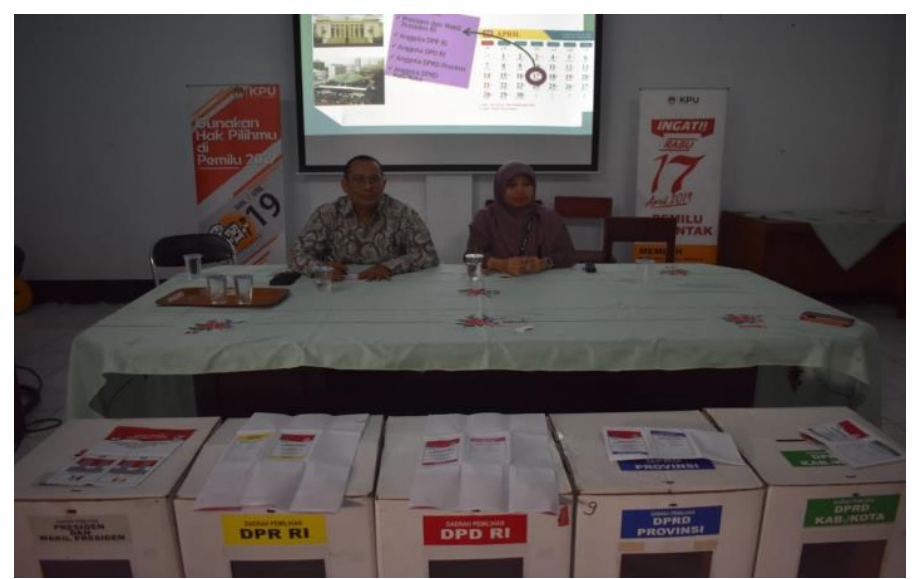

Gambar 6. Pelaksanaan sosialisasi di SMA 13 Kota Depok. 


\section{Rencana Tahapan Berikutnya}

Rencana tahapan berikutnya dari kegiatan Sosialisasi Pemilu 2019 ini adalah kegiatan Sosialisasi Pemilihan Umum Kepala Daerah Kota Depok 2020 kepada pemilih pemula di Kota Depok.

\section{SIMPULAN DAN SARAN}

\section{Simpulan}

Dari hasil kegiatan sosialisasi ini dapat disimpulkan bahwa masih banyak pemilih pemula yang belum memahami informasi tentang pemilihan umum 2019 ini. Namun dengan adanya kegiatan ini akan membantu memberikan pemahaman kepada mereka serta mengajak para pemilih pemula ini untuk datang ke TPS menyalurkan suaranya. Terlihat dalam kegiatan ini para peserta banyak juga yang antusias sehingga harapannya tingkat kesadaran memilihnya pun akan meningkat.

\section{Saran}

Perlu lebih banyak lagi kegiatan sosialisasi seperti ini,terutama bagi pemilih pemula.

\section{DAFTAR PUSTAKA}

Harnom, F., Syahrizal, S., \& Valentina, T. R. (2019). Pendidikan Politik Bagi Pemilih Milenial Dalam Memahami Bahaya Vote Broker Oleh Kpu. Nusantara: Jurnal Ilmu Pengetahuan Sosial. Https://Doi.Org/10.31604/Jips.V6i1.2019.1-10

Nur Wardhani, P. S. (2018). Partisipasi Politik Pemilih Pemula Dalam Pemilihan Umum. Jupiis: Jurnal Pendidikan Ilmu-Ilmu Sosial. Https://Doi.Org/10.24114/Jupiis.V10i1.8407

Sutisna, A. (2017). Strategi Peningkatan Literasi Politik Pemilih Pemula Melalui Pendekatan Pembelajaran Kontekstual. Journal Ilmu Sosial Dan Humaniora.

Kpu Kota Depok. Kpu Goes To School Sosialisasi Pemilihan Umum 2019 "Saatnya Yang Muda Bersuara". 2019.

Www.Kemendagri.Go.Id.

Www.Kpu.Go.Id. 